\title{
ANALISA FAKTOR-FAKTOR YANG MEMPENGARUHI SIKAP KONSUMEN PADA IKLAN DIGITAL DI INDONESIA
}

\author{
Wanda Wandoko ${ }^{1}$, Ignatius Enda Panggati ${ }^{2}$ \\ 1,2 Program Sistem Informasi, Universitas Bina Nusantara, Jakarta Indonesia \\ Email: ${ }^{1}$ wwandoko@gmail.com, ${ }^{2}$ ndoghy@gmail.com
}

Submission date: $2020-02-27$

Accepted date: $2020-03-25$

\begin{abstract}
Marketing has now evolved from marketing that focuses on the concept of exchange to the concept of integrated marketing communication (IMC) or marketing communication that is integrated and focuses on relationships with consumers. The development of information technology and the internet plays a major role in the world of IMC, especially in the part of the advertising world, where technology information and the internet developed advertisements into digital advertisements. This study aims to create a research model as a solution to the problem of how to make consumer attitudes towards digital advertising in Indonesia more positive. This study raises consumer attitudes on digital advertising in Indonesia as variables that provide solutions, namely the entertainment (informational) variable, informativenes (informativeness), and credibility as the antecedent variable of consumer attitudes towards digital advertising (ATDID), and the purchase intention variable as an impact of consumer attitudes towards digital advertising. The results of this study are the research model framework, and the operationalization of variables that can be used to conduct quantitative research, with the aim of finding relationships between these variables, which can later be made as a reference in improving consumer attitudes towards digital advertising that are expected to increase buying intentions.
\end{abstract}

Keywords: Digital Advertising, Entertainment, Informativeness, Credibility, Consumer Attitude

\begin{abstract}
ABSTRAK
Pemasaran saat ini telah berkembang dari pemasaran yang berfokus pada konsep pertukaran menjadi konsep integrated marketing communication (IMC) atau komunikasi marketing yang terintegrasi dan berfokus pada hubungan dengan konsumen perkembangan teknologi informasi dan internet berperan besar dalam dunia IMC, terutama dalam bagian dunia periklanan, dimana teknologi informasi dan internet mengembangkan iklan menjadi iklan digital. Penelitian ini bertujuan untuk membuat model penelitian sebagai solusi atas permasalahan bagaimana membuat sikap konsumen pada iklan digital di Indonesia menjadi lebih positif. Penelitian ini mengangkat sikap konsumen pada iklan digital di Indonesia sebagai variabel yang memberikan solusi, yaitu variabel entertainment (hiburan), informativenes (keinformatifan), dan credibility (kredibilitas) sebagai variabel anteseden dari Sikap konsumen terhadap iklan digital (ATDID), dan variabel niat membeli sebagai dampak dari Sikap konsumen terhadap iklan digital. Hasil dari penelitian ini adalah framework model penelitian, dan operasionalisasi variabel yang dapat digunakan untuk melakukan penelitian kuantitatif, dengan tujuan untuk mencari hubungan antara variabel tersebut, yang nantinya dapat dibuat sebagai acuan dalam meningkatkan sikap konsumen pada iklan digital yang diharapkan dapat meningkatkan intensi membeli.
\end{abstract}

Kata Kunci: Iklan Digital, entertainment, informativeness, credibility, Sikap Konsumen

\section{PENDAHULUAN}

Pemasaran saat ini telah berkembang dari pemasaran yang berfokus pada konsep pertukaran menjadi konsep integrated marketing communication (IMC) atau komunikasi marketing yang terintegrasi dan berfokus pada hubungan dengan konsumen (Belch \& Belch, 2015). Perkembangan teknologi informasi dan internet berperan besar dalam dunia IMC, terutama dalam bagian dunia periklanan, dimana teknologi informasi dan internet mengembangkan iklan menjadi iklan digital. Iklan digital merupakan industri yang saat ini sedang berkembang di beberapa belahan dunia (AppNExus, 2018). Walaupun pada tahun 2019 kondisi ekonomi di dunia masih belum dalam keadaan yang baik, secara global iklan digital di dunia diperkirakan akan tetap tumbuh sebesar $17.6 \%$ menjadi 333.25 milyar dolar Amerika. Nilai ini, yaitu perkiraan total belanja iklan digital pada tahun 2019 akan melampaui untuk pertama kalinya dari 1/2 (setengah) total belanja iklan di media secara keseluruhan (Jasmine Enberg, 2019). 
Dunia industri periklanan digital di Indonesia juga mengalami peningkatan, bahkan menurut laporan dari AppNexus (2018) , dunia industri periklanan digital di Indonesia merupakan salah satu negara dengan pertumbuhan industri periklanan yang tinggi (AppNExus, 2018). Namun walaupun dunia periklanan media di Indonesia mempunyai pertumbuhan yang tinggi, angka belanja iklan di Indonesia masih didominasi oleh media iklan TV (eMarketer, 2016). Perusahaan di Indonesia masih banyak berinvestasi di iklan TV dibandingkan di iklan digital.

Pada prinsip-prinsip pemasaran, sikap merupakan evaluasi, perasaan, dan kecenderungan seseorang yang secara konsisten menyukai atau tidak menyukai suatu objek atau gagasan. Sikap menempatkan orang pada kerangka berpikir tentang menyukai atau tidak menyukai sesuatu, bergerak mendekat atau menjauh dari hal itu. Maka kreatifitas dan ekspresi diri adalah diantara hal-hal terpenting di dunia. Sikap sulit berubah. Sikap seseorang membentuk sebuah pola, dan mengubahnya membutuhkan banyak penyesuaian yang sulit dalam sikap-sikap lainnya. Jadi, perusahaan sebaiknya mencoba mencocokkan produknya kedalam sikap yang nyata tanpa mengubahnya (Amstrong dan Kottler, 1997).

Sikap (attitude) adalah suatu kecenderungan yang dipelajari untuk memberikan respon secara konsisten terhadap suatu objek yang diberikan, seperti halnya suatu merk. Sikap tergantung pada sistem nilai dari seorang individu yang mewakili standar pribadi tentang baik dan buruk, benar dan salah, dan seterusnya, oleh karena itu sikap cenderung lebih tahan lama dan kompleks dibandingkan dengan kepercayaan (Charles W. Lamb, Joseph F. Hair, 2001).

Iklan adalah salah satu bentuk dari komunikasi pemasaran yang mengirimkan informasi mengenai brand (merek) atau produk ke konsumen dengan tujuan untuk mendorong persepsi positif dari konsumen, yang nantinya akan berpengaruh pada sikap dari konsumen tersebut (Lee et al., 2016). Penelitian dari Eze dan Lee (2012) menyebutkan bahwa sikap konsumen pada iklan merupakan indikator penting dalam meningkatkan efektivitas dari iklan (Eze \& Lee, 2012). Pemasaran dan agensi iklan digital perlu mengerti pentingnya sikap konsumen pada iklan digital untuk meningkatkan pengaruhnya pada niat beli mereka, sehingga perusahaan pemegang merek di indonesia akan meningkatkan investasi mereka di iklan digital.

Penelitian ini mengambil sikap konsumen pada iklan digital sebagai fokus utama penelitian.
Penelitian penelitian terdahulu menyebutkan bahwa terdapat beberapa faktor yang berpengaruh terhadap sikap konsumen pada iklan. Penelitian dari Tsang, Ho, And Liang menyimpulkan bahwa unsur entertainment (hiburan), credibility (kredibilitas) dan irritation (gangguan) terbukti berpengaruh signifikan terhadap sikap konsumen pada iklan digital mobile (Tsang et al., 2004). Penelitian dari Fatima dan Abbas (2016) menyimpulkan bahwa variabel entertainment, information (informasi), credibility (kredibilitas) dan personalization (personalisasi) mempunyai pengaruh positif dan signifikan terhadap sikap konsumen pada iklan digital (Fatima \& Abbas, 2016).

Penelitian ini bertujuan untuk membuat model penelitian untuk meningkatkan sikap konsumen terhadap iklan digital di Indonesia. Dalam mengembangkan model penelitian, penelitian ini selain mempelajari dan mempertimbangkan penelitian terdahulu, penelitian ini juga mempertimbangkan perilaku konsumen digital di Indonesia.

\section{METODE PENELITIAN}

Penelitian ini menggunakan metode literature review sebagai metode utama untuk membentuk model penelitian. Berdasarkan penelitian sebelumnya yang sudah diterbitkan pada jurnal ternama, dengan fokus penelitian sikap konsumen pada iklan digital, peneliti melakukan melakukan klasifikasi variabel-variabel serta hubungannya dengan variabel yang lainnya. Selain itu peneliti melakukan pengamatan dan wawancara dengan para praktisi dan konsumen dibidang iklan digital di Indonesia, untuk memahami perilaku konsumen digital di Indonesia.

\section{HASIL DAN PEMBAHASAN}

Dengan pertimbangan dari penelitian penelitian terdahulu, penelitian ini mengusulkan hipotesa "Keinformatifan mempunyai pengaruh positif dan signifikan terhadap ATDID" sebagai H3 - hipotesa ketiga.

\section{Kredibilitas (CRD)}

Credibility atau kredibilitas merupakan basis dari kepercayaan konsumen terhadap merek (Zedan \& Salem, 2016). Kredibilitas merek dapat ditingkatkan melalui iklan sebagai media komunikasi antara merek dengan konsumen. Menurut MacKenzie dan Lutz pada tahun 1989, definisi dari credibility advertising atau kredibilitas iklan adalah tingkatan sampai dimana konsumen mempersepsikan pernyataan tentang merek dalam 
iklan digital itu dapat dipercaya, dan jujur (Le \& Nguyen, 2014; Mackenzie \& Lutz, 1989; Zedan \& Salem, 2016). Dalam penelitian ini, definisi dari kredibilitas adalah tingkatan sampai dimana konsumen mempunyai persepsi bahwa pernyataan dalam iklan digital dapat dipercaya dan jujur. Penelitian penelitian terdahulu banyak yang mengangkat kredibilitas sebagai salah satu anteseden. Penelitian dari Le dan Nguyen menyimpulkan bahwa kredibilitas merupakan anteceden paling berpengaruh terhadap sikap konsumen pada iklan digital mobile. Penelitian dari Salem (2016) juga menyimpulkan bahwa kredibilitas mempunyai pengaruh terhadap sikap konsumen pada iklan digital SMS (Zedan \& Salem, 2016).

Dengan pertimbangan penelitian penelitian terdahulu, penelitian ini mengusulkan hipotesa "kredibilitas mempunyai pengaruh positif dan signifikan terhadap ATDID" sebagai H4 - Hipotesa ke empat.

Berdasarkan pertimbangan dari kajian teori, penelitian penelitian terdahulu, dan perilaku konsumen digital di Indonesia, penelitian ini mengusulkan model penelitian yang ditampilkan dalam Gambar 1.

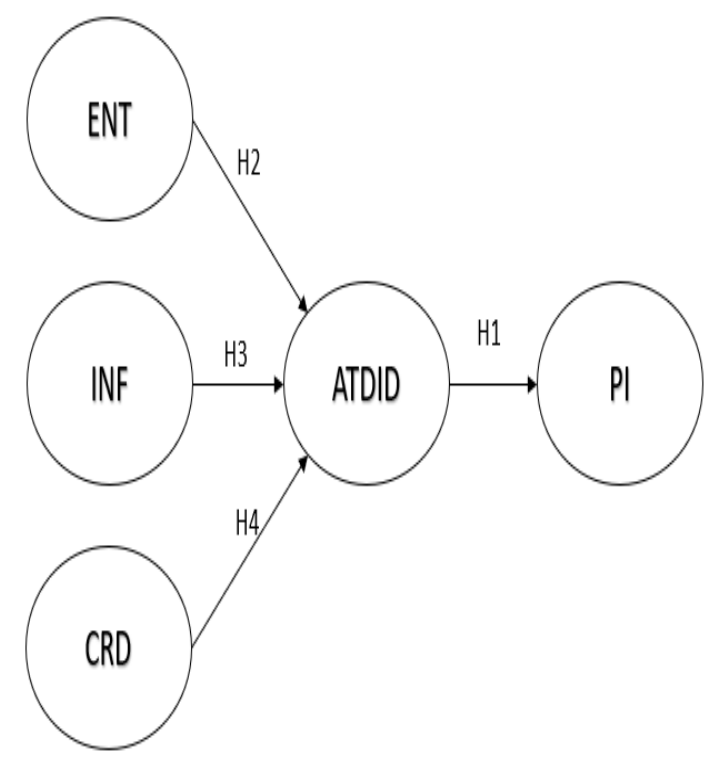

Sumber : (Wanda Wandoko, 2019)

Gambar 1. Usulan Model Penelitian

$\begin{array}{ll}\text { ATDID } & \text { : Sikap konsumen terhadap iklan digital } \\ \text { PI } & : \text { Niat membeli } \\ \text { ENT } & : \text { Hiburan dari iklan digital } \\ \text { INF } & : \text { Keinformatifan dari iklan digital } \\ \text { CRD } & : \text { Kredibilitas dari iklan digital }\end{array}$

Hipotesa - hipotesa yang dibentuk untuk penelitian ini adalah sebagai berikut:

1. ATDID mempunyai pengaruh positif dan signifikan terhadap niat membeli (PI) - H1

2. Hiburan (ENT) mempunyai pengaruh positif dan signifikan terhadap ATDID - $\mathrm{H} 2$

3. Keinformatifan (INF) mempunyai pengaruh positif dan signifikan terhadap ATDID - H3

4. Kredibilitas (CRD) mempunyai pengaruh positif dan signifikan terhadap ATDID - H4

\section{Pengembangan instrumen}

Operasional dari variabel keinformatifan (INF) menggunakan adaptasi dari penelitian (Wolin et al., 2015; Zedan \& Salem, 2016). Indikator untuk variabel Keinformatifan ada 4, yaitu:

1. Iklan digital merupakan sumber informasi alternatif tentang penjualan

2. Iklan digital memberi informasi tentang brand dengan produk, fitur yang saya cari

3. Iklan digital membantu menyediakan informasi terkini tentang produk yang ada di pasar

4. Informasi dalam iklan digital mudah dimengerti

Operasional dari variabel Hiburan (ENT) menggunakan adaptasi dari (Wolin et al., 2015; Zabadi et al., 2012; Zedan \& Salem, 2016). Variabel Hiburan terdapat 4 indikator, yaitu:

1. Iklan digital lebih menarik dari iklan media lain.

2. Terkadang saya senang ketika mengingat tentang apa yang saya lihat, atau dengar di iklan digital

3. Secara umum, iklan digital membuat saya terhibur

4. Secara keseluruhan, iklan digital mempunyai elemen seperti visual, audio, video, konsep, kreatifitas yang menarik

Operasional dari variabel Kredibilitas (CRD) menggunakan adaptasi dari (Zabadi et al., 2012; Zedan \& Salem, 2016). Variabel kredibilitas terdapat 4 indikator untuk yaitu:

1. Saya menggunakan iklan digital sebagai referensi ketika berbelanja.

2. Saya percaya kepada iklan digital

3. Konten dari iklan digital dapat dipercaya

4. Iklan digital akan menjadi iklan yang utama di masa depan 
Operasional dari variabel sikap konsumen pada iklan digital di Indonesia ATDID menggunakan adaptasi dari (Chowdhury et al., 2006; Wolin et al., 2015). Variabel ATIDID mempunyai 4 indikator yaitu:

1. Secara keseluruhan, saya menganggap iklan digital positif

2. Secara keseluruhan, saya suka iklan digital

3. Saya lebih suka iklan digital daripada iklan media lain

4. Brand yang menggunakan iklan digital, mempunyai kualitas lebih baik dibandingkan brand yang tidak menggunakan

Operasional dari variabel niat membeli (PI) menggunakan adaptasi dari (Xu, 2006; Zedan \& Salem, 2016). Variabel niat membeli terdapat 4, yaitu:

1. Saya akan mempertimbangkan produk yang diiklankan pada iklan digital sebagai pilihan pertama ketika belanja.

2. Saya akan mencari informasi tentang produk yang diiklankan pada iklan digital, setelah melihatnya.

3. Saya menyarankan teman saya untuk memilih produk yang menggunakan iklan digital dibandingkan produk yang tidak.

4. Saya berniat untuk membeli produk yang diiklankan setelah melihat iklan digital dari produk tersebut.

\section{KESIMPULAN}

Berdasarkan penelitian terdahulu dan memperhatikan perilaku konsumen di Indonesia, untuk menjawab permasalahan utama, peneliti mengusulkan framework model penelitian seperti Gambar 1 di atas, yang menempatkan hiburan dari iklan digital (ENT), keinformatifan dari iklan digital (INF), kredibilitas dari iklan digital (CRD) sebagai anteseden dari sikap konsumen terhadap iklan digital (ATDID), dan sikap konsumen terhadap iklan digital mempunyai pengaruh terhadap niat membeli konsumen (PI).

Model penelitian dalam penelitian ini diharapkan dapat dijadikan referensi untuk pembuatan penelitian kuantitatif tentang sikap konsumen iklan digital terhadap iklan digital, sehingga nantinya dapat digunakan untuk mendukung keputusan para praktisi dalam meningkatkan sikap konsumen iklan digital secara lebih tepat. Implikasi teori dari penelitian ini adalah penelitian ini mengembangkan model penelitian dengan mengembangkan aplikasi teori TRA dalam perilaku konsumen, khususnya sikap konsumen terhadap iklan digital. Penelitian ini juga mengembangkan model penelitian dengan mengembangkan aplikasi konsep hiburan, kredibilitas, dan keinformatifan sebagai anteseden untuk sikap konsumen terhadap iklan digital.

\section{DAFTAR PUSTAKA}

Amstrong dan Kottler. (1997). Prinsip-Prinsip Pemasaran. Erlangga.

AppNExus. (2018). The Digital Advertising Stats You Need.

Belch, G. E., \& Belch, M. A. (2015). Advertising and Promotion An Integrated Marketing Communications Perspective. McGraw Hill.

Charles W. Lamb, Joseph F. Hair, dan C. M. (2001). Pemasaran (Pertama). Salemba Empat.

Chowdhury, H. K., Parvin, N., Weitenberner, C., \& Becker, M. (2006). CONSUMER ATTITUDE TOWARD MOBILE ADVERTISING IN AN EMERGING MARKET: AN EMPIRICAL STUDY. International Journal of Mobile Marketing, 1 .

eMarketer. (2016). Worldwide Ad Spending. In eMarketer (Issue October).

Eze, U. C., \& Lee, C. H. (2012). Consumers ' Attitude towards Advertising. 7(13), 94-108. https://doi.org/10.5539/ijbm.v7n13p94

Fatima, T., \& Abbas, T. (2016). Impact of Advertising Beliefs and Personalization on Attitude towards Advertising; Mediating Role of Advertising Value. International Journal of Business Management and Commerce, 1(2), 10-19.

Jasmine Enberg. (2019). Global Digital Ad Spending 2019 - eMarketer Trends, Forecasts \& Statistics. Emarketer.

Le, T. D., \& Nguyen, B. T. H. (2014). Attitudes toward mobile advertising: A study of mobile web display and mobile app display advertising. Asian Academy of Management Journal, 19(2), 87-103.

Lee, Y.-G., Byon, K. K., Ammon, R., \& Park, S.-B. R. (2016). Golf Product Advertising Value, Attitude Toward Advertising and Brand, and Purchase Intention. Social Behavior and Personality: An International Journal, 44(5), 785-800.

https://doi.org/10.2224/sbp.2016.44.5.785

Mackenzie, S. B., \& Lutz, R. J. (1989). An Empirical Examination of the Structural Antecedents of Attitude toward the Ad in an Advertising Pretesting Context. Source: Journal of Marketing, 5321127(2), 48-65. https://doi.org/10.2307/1251413 
Tsang, M. M., Ho, S., \& Liang, T. (2004). Consumer Attitudes Toward Mobile Advertising: An Empirical Study. 8(3), 65-78.

Wanda Wandoko, I. E. P. (2019). ANALISA

FAKTOR-FAKTOR YANG MEMPENGARUHI SIKAP KONSUMEN PADA IKLAN DIGITAL DI INDONESIA.

Wolin, L. D., Korgaonkar, P., \& Lund, D. (2015). Beliefs, attitudes and behaviour towards Web advertising. International Journal of Advertising, 21(1), 87-113. https://doi.org/10.1080/02650487.2002.11104 918

Xu, D. J. (2006). The Influence of Personalization in Affecting Consumer Attitudes Toward Mobile Advertising in China. Journal of Computer Information Systems, 47(2), 9-19. https://doi.org/Article

Zabadi, A. M. A., Shura, M., \& Elsayed, E. a. (2012). Consumer Attitudes toward SMS Advertising among Jordanian Users. International Journal of Marketing Studies, 4(1), $\quad$ 77-94. https://doi.org/10.5539/ijms.v4n1p77

Zedan, M., \& Salem, Y. (2016). Factors affecting consumer attitudes, intentions and behaviors toward SMS advertising in Palestine. Indian Journal of Science and Technology, 9(4), 114.

https://doi.org/10.17485/ijst/2016/v9i4/80216 
